\title{
VARIABILIDADE DOS ÍNDICES DE COLHEITA DE NUTRIENTES EM GENÓTIPOS DE FEIJOEIRO E SUA RELAÇÃO COM A PRODUÇÃO DE GRÃOS(1)
}

\author{
Adelson Paulo Araújo(2) \& Marcelo Grandi Teixeira ${ }^{(3)}$
}

\begin{abstract}
RESUMO
A identificação de genótipos com elevada acumulação de biomassa e nutrientes, mas com baixo índice de colheita de nutrientes (razão entre conteúdo de nutrientes nos grãos e na parte aérea), pode reduzir a remoção pelas colheitas e aumentar a sustentabilidade agrícola. Evidências de reduzida variabilidade nos índices de colheita em feijoeiro (Phaseolus vulgaris L.) demandam a avaliação de uma ampla gama de genótipos. Este trabalho teve como objetivo avaliar a variabilidade dos índices de colheita de nutrientes e sua relação com a produção de grãos em genótipos de feijoeiro. Foi conduzido um experimento de campo em Seropédica - RJ, com 64 genótipos de feijoeiro em quatro repetições, incluindo 41 cultivares, 12 linhagens de melhoramento e 10 cultivares locais da região Sul. Os índices de colheita foram mensurados a partir das quantidades acumuladas de biomassa e nutrientes nos grãos, caules e palha de vagens produzidos após trilhagem dos grãos. A média da produção de grãos foi de $205 \mathrm{~g} \mathrm{~m}^{-2}$, com índices de colheita médios de biomassa, $\mathrm{N}, \mathrm{P}, \mathrm{K}, \mathrm{Ca}$ e $\mathrm{Mg}$ de 0,62, 0,83, 0,89, 0,58, 0,33 e $0,51 \mathrm{~g} \mathrm{~g}^{-1}$, respectivamente, denotando intensa translocação de $\mathrm{N}$ e $\mathrm{P}$ para os grãos, sendo relativamente estreita a variabilidade desses índices. A massa seca de resíduos após trilhagem dos grãos foi em média de $107 \mathrm{~g} \mathrm{~m}^{-2}$, contendo $2,0,0,15$, $3,6,2,8$ e $1,3 \mathrm{~g} \mathrm{~m}^{-2}$ de $\mathrm{N}, \mathrm{P}, \mathrm{K}$, Ca e Mg, respectivamente, o que indica que esses materiais podem restituir quantidades relativamente elevadas de nutrientes em comparação com as demandas do cultivo. Foram obtidas elevadas correlações fenotípicas e genéticas $(p<0,001)$ : positivas entre produção de grãos e índices de colheita de biomassa e $\mathrm{N}$ e negativas entre produção e teores de $\mathrm{N}$ e $\mathrm{P}$ nos grãos. Como as correlações fenotípicas e genéticas entre rendimento e índice de colheita de $P$ foram menos significativas $(p<0,01)$, foi possível identificar alguns genótipos com baixo índice de colheita de $\mathrm{P}$ e bom rendimento. A seleção de genótipos de feijoeiro para maior rendimento de grãos pode resultar em maiores
\end{abstract}

(1) Recebido para publicação em 22 de março de 2011 e aprovado em 19 de outubro de 2011.

(2) Departamento de Solos, Universidade Federal Rural do Rio de Janeiro - UFRRJ. CEP 23890-000 Seropédica (RJ). E-mail: aparaujo@ufrrj.br

(3) Embrapa Agrobiologia. CEP 23890-000 Seropédica (RJ). E-mail: grandi@cnpab.embrapa.br 
índices de colheita de biomassa e de $\mathrm{N}$, assim como em maiores quantidades de nutrientes nos grãos e menores teores de $\mathrm{N}$ e $\mathrm{P}$ nos grãos.

Termos de indexação: nitrogênio, fósforo, feijão, Phaseolus vulgaris, diversidade.

\title{
SUMMARY: VARIABILITY OF NUTRIENT HARVEST INDICES IN COM- MON BEAN GENOTYPES AND THEIR RELATIONSHIP WITH GRAIN YIELD
}

\begin{abstract}
The use of genotypes with high biomass and nutrient accumulation but low nutrient harvest indices (ratio between nutrient amount in grains and in shoots) could reduce nutrient removal by harvesting and improve agricultural sustainability. The low variability found in the harvest indices in common bean (Phaseolus vulgaris L.) calls for the evaluation of a wide range of genotypes. This study evaluated the variability of nutrient harvest indices and their relationship with grain yield in common bean genotypes. A field experiment was carried out in Seropédica, State of Rio de Janeiro, with 64 bean genotypes (41 cultivars, 12 breeding lines and 10 landraces from the South of Brazil) in four replications. The harvest indices were based on the amounts of biomass and nutrients accumulated in grains, stems and pod hulls after pod threshing. The average grain yield was $205 \mathrm{~g} \mathrm{~m}^{-2}$, with average harvest indices of biomass, $N, P, K, C a$, and $M g$ of $0.62,0.83,0.89,0.58,0.33$, and $0.51 \mathrm{~g} \mathrm{~g}^{-1}$, respectively, indicating an intense translocation of $N$ and $P$ to grains. The variability of these indices was relatively narrow. The residue dry mass after pod threshing was on average $107 \mathrm{~g} \mathrm{~m}^{-2}$, and contained 2.0, 0.15, 3.6, 2.8 and $1.3 \mathrm{~g} \mathrm{~m}^{-2}$ of $\mathrm{N}, \mathrm{P}, \mathrm{K}$, Ca and $\mathrm{Mg}$, respectively, wich suggests that these residues can meet a relatively great part of the crop nutrient demand. The phenotypic and genetic correlations $(p<0.001)$ were high, positive between grain yield and harvest indices of biomass and $N$, and negative between grain yield and $N$ and $P$ grain concentrations. Since the phenotypic and genetic correlations between grain yield and $P$ harvest index were less significant $(p<0.01)$, some genotypes with low $P$ harvest index but good yields could be identified. The selection of common bean genotypes for improved grain yield can result in higher harvest indices of biomass and $N$, and also in larger nutrient amounts in grains and lower $N$ and $P$ grain concentrations.
\end{abstract}

Index terms: nitrogen, phosphorus, common bean, Phaseolus vulgaris, diversity.

\section{INTRODUÇÃO}

A introdução de leguminosas em sistemas de produção assume grande relevância não apenas pelo aporte de $\mathrm{N}$ por meio da fixação biológica de $\mathrm{N}_{2}$, mas também, em uma perspectiva de longo prazo, pelo aumento dos estoques de nutrientes e de matéria orgânica do solo. Entretanto, os benefícios de cultivos de leguminosas de grão para a sustentabilidade da exploração agrícola só podem ser efetivamente logrados caso os resíduos dos cultivos gerados após a colheita dos grãos retornem ao solo (Shah et al., 2003). Os resíduos de cultivos de leguminosas de grãos, dependendo do tipo e da qualidade do material, usualmente contêm de 20 a $80 \mathrm{~kg} \mathrm{ha}^{-1}$ de $\mathrm{N}$, porém em alguns casos podem conter acima de $150 \mathrm{~kg} \mathrm{ha}^{-1}$ de N (Shah et al., 2003). Os resíduos resultantes da trilhagem de grãos de cultivares de feijoeiro (Phaseolus vulgaris L.) apresentaram massa seca entre 0,6 e 1,5 $\mathrm{Mg}^{-1}$ e continham entre 5 e $12 \mathrm{~kg} \mathrm{ha}^{-1}$ de $\mathrm{N}$ e entre 0,4 e
$1,0 \mathrm{~kg} \mathrm{ha}{ }^{-1}$ de $\mathrm{P}$, correspondendo em média a $15 \mathrm{e}$ $11 \%$ do total de $\mathrm{N}$ e $\mathrm{P}$, respectivamente, acumulados pela cultura quando da maturação dos grãos (Araújo \& Teixeira, 2003).

No Brasil ainda predomina amplamente a colheita manual do feijoeiro, que respondeu em 2005 por $54 \%$ da quantidade colhida de feijão de cor e $76 \%$ de feijão-preto (IBGE, 2006). Na colheita mecanizada do feijão, os resíduos da parte aérea da cultura mantêm-se sobre o solo até sua completa decomposição, enquanto nas colheitas manual e semimecanizada a parte aérea é arrancada e transportada para locais onde os grãos são trilhados. Para que sejam adequadamente manejados, é necessário demonstrar aos agricultores que esses resíduos apresentam valor como fonte de matéria orgânica e nutrientes para o crescimento dos cultivos subsequentes (Shah et al., 2003). A substituição das práticas de queima de resíduos por seu adequado manejo pode diminuir a emissão de gases para a atmosfera, o que reduz os impactos da agricultura 
no efeito estufa, além de incorporar quantidades substanciais de matéria orgânica ao solo (Lal, 2003).

Os incrementos de produtividade dos cereais nas últimas décadas têm sido obtidos principalmente por meio de aumento na fotossíntese por unidade de área, resultante de práticas agronômicas como irrigação e aplicação de fertilizantes, e do aumento da partição da biomassa vegetal para o produto colhido (Richards, 2000). Cultivares modernas de soja apresentaram taxas fotossintéticas, biomassa de parte aérea e índice de colheita superiores aos de cultivares predecessoras (Jin et al., 2010). A seleção para rendimento de grãos e caracteres como resistência a estresses bióticos e abióticos, hábito de crescimento e dias para maturação tem sido objeto do melhoramento do feijoeiro, com o intuito de desenvolver cultivares com desempenho superior ou mais adaptadas a ambientes específicos (Tar'an et al., 2002). Entretanto, enquanto em cereais com autopolinização a alteração da partição da biomassa propiciou maior produção de grãos, os progressos no rendimento de grãos no feijoeiro têm sido mais modestos (Kelly et al., 1998). Além disso, o maior custo energético inerente à produção de grãos ricos em proteína pode limitar futuros ganhos de produtividade em leguminosas de grão (MunierJolain \& Salon, 2005).

A biomassa de parte aérea, o índice de colheita (correspondente à razão entre massa de grãos e de parte aérea) e os dias para maturação constituem os três componentes fisiológicos com maior influência na produção de grãos de feijão (Yan \& Wallace, 1995). A descrição da produção de grãos em função da biomassa e do índice de colheita produz um modelo de simples compreensão, mas não elucida os complexos processos que poderiam permitir futuros incrementos de produtividade (Egli, 2006). A seleção para produção de biomassa, índice de colheita e dias para maturação pode resultar em incrementos de produção do feijoeiro, apesar de tornar-se necessária uma seleção simultânea em virtude das relações genéticas entre esses três componentes (Kelly et al., 1998). Sinclair (1998) sugere que o desenvolvimento de cultivos com maior índice de colheita deve iniciarse com incremento na acumulação de nutrientes, em vez de uma simples alteração na partição de biomassa.

A avaliação da variação genética no crescimento vegetal em solos com limitações edáficas e o uso de caracteres nutricionais no melhoramento vêm sendo propostos como estratégias para aumentar a eficiência dos fertilizantes e para obter maior produtividade em solos de baixa fertilidade ou em condições de pequena disponibilidade de insumos. Maior eficiência de utilização de $\mathrm{P}$ pode ser obtida por genótipos que retenham $\mathrm{P}$ nos tecidos vegetativos, mantendo maior atividade fotossintética no dossel, reduzindo o índice de colheita de $\mathrm{P}$ e minimizando o teor de $\mathrm{P}$ nos grãos. Lynch \& White (1992) propuseram que um ideótipo de feijoeiro para eficiência de $\mathrm{N}$ deve incluir intensa aquisição deste nutriente, translocação tardia deste para as sementes, alto índice de colheita de $\mathrm{N}$ e baixo teor deste nos grãos. Araújo \& Teixeira (2003) consideram que o ideótipo para um sistema de produção sob baixos insumos deve privilegiar materiais com elevada absorção de nutrientes e produção de biomassa, porém com pequena translocação de nutrientes para os grãos, reduzindo a retirada de nutrientes do sistema e otimizando a ciclagem de nutrientes pelas folhas senescentes e dos resíduos ao final do cultivo.

Em Phaseolus vulgaris, a variabilidade genética dentro de um mesmo grupo comercial de grão é considerada estreita, o que é atribuído aos estritos requerimentos de tipo de grão impostos pelos processadores e consumidores, ao uso limitado de germoplasma exótico e às estratégias conservadoras adotadas pelos programas de melhoramento (Singh, 2001). Há evidências de reduzida variabilidade genética para o índice de colheita de grãos e os índices de colheita de nutrientes em feijoeiro (Araújo \& Teixeira, 2003). Assim, deve-se avaliar uma ampla gama de genótipos, representativa de diferentes tipos de grãos e fenologias, incluindo inclusive cultivares locais de ampla diversidade, buscando-se identificar materiais mais promissores.

Nesse contexto, este trabalho teve como objetivo avaliar a variabilidade dos índices de colheita de nutrientes e sua relação com a produção de grãos em genótipos de feijoeiro.

\section{MATERIAL E MÉTODOS}

Foi conduzido um experimento de campo entre maio e agosto de 2003, em solo Argissolo VermelhoAmarelo distrófico, na Embrapa Agrobiologia, em Seropédica - RJ, situado na latitude de $22^{\circ} 45^{\prime} \mathrm{S}$, longitude de $43^{\circ} 41^{\prime} \mathrm{W}$ e altitude de $33 \mathrm{~m}$, com clima Aw na classificação de Köppen. O delineamento foi em blocos ao acaso com quatro repetições, avaliandose 64 genótipos de feijoeiro (Quadro 1): 41 cultivares comerciais tradicionais e modernas, 12 linhagens oriundas do Ensaio Preliminar de Linhagens de 2001 (grupos comerciais de grãos tipo Jalo, Mulatinho, Iraí e Carioca), 10 cultivares locais coletadas junto a agricultores da região Sul (Rodrigues et al., 2002), previamente avaliadas nas condições de Seropédica, e um genótipo não nodulante. Os materiais avaliados cobriram os três hábitos de crescimento predominantes em cultivos comerciais (I, II e III), uma ampla gama de tamanhos de semente (14 a $51 \mathrm{~g}$ por 100 sementes) e diversos tipos comerciais de grão (Quadro 1). 
Quadro 1. Massa de 100 sementes, hábito de crescimento, dias para floração e para maturação de grãos (em dias após emergência - DAE), produção de grãos (13\% de umidade) e índice de colheita de biomassa e de nutrientes, de 64 genótipos de feijoeiro em campo

\begin{tabular}{|c|c|c|c|c|c|c|c|c|c|c|c|}
\hline \multirow{2}{*}{ Genótipo $^{(1)}$} & \multirow{2}{*}{$\begin{array}{c}\text { Massa de } \\
100 \\
\text { sementes }\end{array}$} & \multirow{2}{*}{ Hábito $^{(2)}$} & \multirow{2}{*}{ Floração } & \multirow{2}{*}{ o Maturação } & \multirow{2}{*}{$\begin{array}{c}{ }_{0}^{\text {Produção }} \\
\text { de grãos }\end{array}$} & \multirow{2}{*}{$\begin{array}{l}\text { Índice de } \\
\text { colheita }\end{array}$} & \multicolumn{5}{|c|}{ Índice de colheita de nutrientes } \\
\hline & & & & & & & $\mathbf{N}$ & $\mathbf{P}$ & $\mathbf{K}$ & $\mathbf{C a}$ & Mg \\
\hline & $\mathrm{g}$ & & & DAE & $\mathrm{g} \mathrm{m}^{-2}$ & & & $-m g$ & & & \\
\hline Alessa & 32,6 & I & 29 & 70 & 116 & 551 & 729 & 864 & 506 & 369 & 494 \\
\hline Bolinha & 30,7 & $\mathrm{I}$ & 29 & 76 & 212 & 621 & 844 & 897 & 600 & 404 & 507 \\
\hline Constanza & 50,7 & I & 29 & 82 & 244 & 635 & 846 & 888 & 609 & 273 & 479 \\
\hline Goiano Precoce & 35,4 & $\mathrm{I}$ & 30 & 75 & 223 & 642 & 826 & 898 & 575 & 316 & 483 \\
\hline Iraí & 35,7 & $\mathrm{I}$ & 29 & 75 & 211 & 637 & 845 & 887 & 632 & 384 & 531 \\
\hline Kaboon & 42,7 & $\mathrm{I}$ & 29 & 75 & 210 & 600 & 836 & 893 & 555 & 270 & 477 \\
\hline Aporé & 19,0 & II & 35 & 81 & 192 & 662 & 841 & 888 & 677 & 384 & 559 \\
\hline BAT 477 & 19,1 & II & 34 & 83 & 175 & 617 & 842 & 899 & 560 & 336 & 509 \\
\hline BAT76 & 16,2 & II & 33 & 81 & 160 & 545 & 812 & 861 & 465 & 232 & 428 \\
\hline Diamante Negro & 18,9 & II & 36 & 83 & 197 & 595 & 847 & 892 & 550 & 348 & 489 \\
\hline FT Bonito & 23,1 & II & 34 & 81 & 223 & 645 & 835 & 893 & 597 & 299 & 555 \\
\hline FT Nobre & 18,9 & II & 36 & 85 & 196 & 600 & 847 & 888 & 595 & 303 & 517 \\
\hline Guapo Brilhante & 17,5 & II & 36 & 79 & 235 & 633 & 844 & 889 & 561 & 355 & 510 \\
\hline IAPAR 31 & 27,4 & II & 37 & 89 & 161 & 654 & 818 & 876 & 697 & 392 & 533 \\
\hline IAPAR 44 & 19,1 & II & 36 & 80 & 209 & 621 & 814 & 879 & 565 & $33 \overline{5}$ & 547 \\
\hline IAPAR 81 & 25,4 & II & 36 & 82 & 201 & 603 & 840 & 883 & 534 & 293 & 494 \\
\hline ICA Pijao & 23,0 & II & 36 & 84 & 202 & 586 & 853 & 903 & 605 & 273 & 486 \\
\hline Jalo EEP & 36,3 & II & 32 & 76 & 234 & 617 & 849 & 898 & 624 & 248 & 445 \\
\hline Jalo Precoce & 42,2 & II & 29 & 76 & 214 & 593 & 805 & 863 & 504 & 292 & 475 \\
\hline Manteigão Fosco & 49,1 & II & 29 & 77 & 239 & 623 & 830 & 880 & 533 & 247 & 500 \\
\hline Manteigão PC & 39,8 & II & 29 & 79 & 256 & 638 & 842 & 899 & 565 & 362 & 578 \\
\hline Negro Argel & 17,2 & II & 36 & 81 & 169 & 598 & 843 & 884 & 582 & 329 & 481 \\
\hline Perola & 25,7 & II & 34 & 84 & 224 & 636 & 827 & 892 & 673 & 418 & 565 \\
\hline Minuano & 24,1 & II & 35 & 81 & 178 & 613 & 818 & 869 & 602 & 368 & 511 \\
\hline Rico 23 & 22,1 & II & 36 & 82 & 185 & 630 & 859 & 893 & 591 & 314 & 518 \\
\hline Rio Negro & 16,9 & II & 36 & 82 & 158 & 568 & 827 & 880 & 527 & 229 & 422 \\
\hline Rio Tibagi & 14,4 & II & 35 & 85 & 187 & 625 & 865 & 913 & 539 & 360 & 477 \\
\hline Rosinha & 21,3 & II & 34 & 78 & 174 & 592 & 791 & 857 & 573 & 366 & 472 \\
\hline Roxo 90 & 20,2 & II & 37 & 86 & 166 & 609 & 842 & 888 & 572 & 335 & 519 \\
\hline Rubi & 19,9 & II & 37 & 82 & 198 & 614 & 829 & 888 & 548 & 314 & 519 \\
\hline Rudá & 21,2 & II & 35 & 82 & 208 & 634 & 848 & 901 & 569 & 400 & 547 \\
\hline Safira & 18,5 & II & 34 & 79 & 194 & 583 & 841 & 896 & 542 & 258 & 480 \\
\hline Valente & 21,2 & II & 37 & 84 & 203 & 600 & 839 & 892 & 553 & 276 & 482 \\
\hline Xamego & 17,4 & II & 35 & 82 & 171 & 600 & 851 & 891 & 585 & 277 & 439 \\
\hline Xodó & 19,1 & II & 34 & 84 & 187 & 588 & 835 & 879 & 564 & 367 & 503 \\
\hline Capixaba Precoce & 21,1 & III & 31 & 79 & 228 & 645 & 877 & 898 & 610 & 329 & 522 \\
\hline Carioca & 19,2 & III & 35 & 82 & 186 & 652 & 844 & 899 & 653 & 338 & 564 \\
\hline Flor de Mayo & 30,8 & III & 33 & 78 & 183 & 682 & 829 & 895 & 687 & 427 & 618 \\
\hline Ouro Negro & 20,4 & III & 34 & 82 & 227 & 681 & 888 & 931 & 666 & 346 & 600 \\
\hline Porto Real & 25,8 & III & 33 & 79 & 224 & 655 & 874 & 911 & 599 & 328 & 513 \\
\hline Puebla 152 & 21,3 & III & 36 & 86 & 223 & 651 & 856 & 899 & 648 & 346 & 506 \\
\hline Pop 15 & 46,5 & I & 30 & 75 & 232 & 643 & 856 & 895 & 594 & 344 & 552 \\
\hline Pop 39 & 23,6 & II & 36 & 80 & 153 & 613 & 827 & 882 & 510 & 325 & 514 \\
\hline Pop 47 & 33,8 & $\mathrm{I}$ & 30 & 75 & 229 & 646 & 840 & 896 & 639 & 281 & 544 \\
\hline Pop 50 & 41,6 & I & 32 & 76 & 239 & 584 & 818 & 874 & 588 & 298 & 505 \\
\hline Pop 56 & 34,7 & I & 29 & 76 & 183 & 596 & 825 & 872 & 546 & 266 & 495 \\
\hline Pop 58 & 32,0 & I & 30 & 76 & 217 & 633 & 835 & 885 & 616 & 327 & 479 \\
\hline Pop 59 & 39,0 & I & 29 & 75 & 280 & 683 & 878 & 909 & 578 & 482 & 648 \\
\hline Pop 60 & 36,6 & $\mathrm{I}$ & 32 & 76 & 234 & 708 & 866 & 920 & 662 & 298 & 602 \\
\hline Pop 62 & 42,6 & $\mathrm{I}$ & 29 & 75 & 206 & 583 & 795 & 842 & 525 & 259 & 427 \\
\hline Pop 71 & 38,9 & $\mathrm{I}$ & 29 & 75 & 264 & 652 & 853 & 889 & 564 & 429 & 538 \\
\hline Linha 08 I & 38,8 & $\mathrm{I}$ & 29 & 75 & 254 & 610 & 810 & 869 & 513 & 289 & 499 \\
\hline Linha $32 \mathrm{I}$ & 35,6 & I & 30 & 75 & 202 & 599 & 819 & 863 & 518 & 283 & 459 \\
\hline Linha $44 \mathrm{I}$ & 34,8 & I & 29 & 75 & 232 & 623 & 810 & 876 & 570 & 352 & 567 \\
\hline Linha $04 \mathrm{M}$ & 17,4 & II & 37 & 84 & 167 & 600 & 829 & 881 & 544 & 258 & 532 \\
\hline Linha $05 \mathrm{M}$ & 21,5 & II & 35 & 82 & 230 & 652 & 866 & 918 & 636 & 396 & 607 \\
\hline Linha $27 \mathrm{M}$ & 18,5 & II & 36 & 83 & 203 & 584 & 808 & 861 & 554 & 379 & 541 \\
\hline Linha $29 \mathrm{~J}$ & 33,9 & II & 30 & 75 & 228 & 609 & 811 & 856 & 561 & 243 & 449 \\
\hline Linha $33 \mathrm{~J}$ & 39,5 & II & 30 & 75 & 247 & 618 & 836 & 888 & 579 & 298 & 493 \\
\hline Linha $45 \mathrm{~J}$ & 36,1 & II & 30 & 75 & 190 & 598 & 810 & 870 & 531 & 240 & 470 \\
\hline Linha $11 \mathrm{C}$ & 25,8 & III & 36 & 80 & 214 & 635 & 826 & 892 & 609 & 363 & 532 \\
\hline Linha $22 \mathrm{C}$ & 26,3 & III & 37 & 86 & 199 & 614 & 835 & 888 & 643 & 418 & 560 \\
\hline Linha $35 \mathrm{C}$ & 24,7 & III & 37 & 84 & 191 & 618 & 835 & 885 & 633 & 318 & 521 \\
\hline NORH54 & 17,7 & II & 35 & 80 & 113 & 536 & 766 & 843 & 462 & 335 & 419 \\
\hline Média & & - & 33 & 80 & 205 & 619 & 834 & 886 & 581 & 327 & 512 \\
\hline Mínimo & 14,4 & - & 29 & 70 & 113 & 536 & 729 & 842 & 462 & 229 & 419 \\
\hline Máximo & 50,7 & - & 37 & 89 & 280 & 708 & 888 & 931 & 697 & 482 & 648 \\
\hline CV $(\%)$ & & - & . & & 18,48 & 4,70 & 3,83 & 2,80 & 10,62 & 27,42 & 13,01 \\
\hline
\end{tabular}

(1) Pop: cultivares locais coletadas junto a agricultores da região Sul (Rodrigues et al., 2002); Linha: linhagens do Ensaio Preliminar de Linhagens de 2001 da Embrapa (I, M, J e C: grupos comerciais de grãos tipo Iraí, Mulatinho, Jalo e Carioca, respectivamente); NORH54: genótipo não nodulante. ${ }^{(2)}$ Hábito de crescimento: I: ereto determinado; II: ereto indeterminado; III: prostrado indeterminado. 
Análises do solo da área experimental na camada de 0-20 cm (Embrapa, 1997) indicaram: $\mathrm{pH}$ em água de 5,1,1,9 $\mathrm{cmol}_{\mathrm{c}} \mathrm{kg}^{-1}$ de Ca, $1,5 \mathrm{cmol}_{\mathrm{c}} \mathrm{kg}^{-1}$ de $\mathrm{Mg}$, $0,18 \mathrm{cmol}_{\mathrm{c}} \mathrm{kg}^{-1} \mathrm{de} \mathrm{K}, 0,1 \mathrm{cmol}_{\mathrm{c}} \mathrm{kg}^{-1} \mathrm{de} \mathrm{Al}, 1,2 \mathrm{cmol}_{\mathrm{c}} \mathrm{kg}^{-1}$ de $\mathrm{H}, 3 \mathrm{mg} \mathrm{kg}{ }^{-1}$ de $\mathrm{P}$ disponível, 6,9 $\mathrm{g} \mathrm{kg}^{-1}$ de C orgânico e textura franco-argiloarenosa. O solo foi arado, gradeado e sulcado, e cada parcela foi demarcada, com três linhas de $4 \mathrm{~m}$ de comprimento espaçadas de $0,5 \mathrm{~m}$ entre si. Os fertilizantes foram colocados no fundo do sulco de plantio, nas doses de 25, 40 e $40 \mathrm{~kg} \mathrm{ha}^{-1}$ de N, P e K, respectivamente, em formulação comercial. Foram semeadas 15 sementes por metro. Aos 25 dias do plantio, foi aplicado herbicida para controle de plantas invasoras. Aos 30 dias após o plantio, próximo ao estádio de floração, foi efetuada uma aplicação em cobertura de $30 \mathrm{~kg} \mathrm{ha}^{-1}$ de $\mathrm{N}$ na forma de ureia. Cada cultivar foi caracterizada quanto ao hábito de crescimento da planta, sendo determinados os dias para floração e maturação dos grãos em cada parcela experimental. Os dados climáticos durante o período experimental foram obtidos na Estação Experimental de Seropédica, da Empresa de Pesquisa Agropecuária do Estado do Rio de Janeiro - PESAGRO-RIO, sendo: temperatura média de $21,2{ }^{\circ} \mathrm{C}$, umidade relativa do ar de $70 \%$, evaporação de tanque de $3,1 \mathrm{~mm}$ dia $^{-1}$ e radiação solar de $6,9 \mathrm{~h} \mathrm{dia}^{-1}$. O experimento foi irrigado semanalmente.

Quando da maturação de grãos de cada genótipo, as plantas na linha central de cada parcela, correspondendo a uma área útil de $1,5 \mathrm{~m}^{2}$, foram colhidas ao nível do solo e colocadas em sacos de pano. As plantas e vagens foram contadas; as vagens, trilhadas manualmente; e as sementes, contadas e pesadas. Os caules e a palha das vagens foram secos em estufa, pesados e moídos. Uma amostra das sementes foi seca em estufa, fornecendo o teor de umidade e a massa de 100 sementes, e moída. A produção de grãos foi padronizada para $13 \%$ de umidade.

Nos caules, na palha das vagens e nos grãos colhidos na maturação, foi determinado o teor de $\mathrm{N}$ pelo método semimicro Kjeldahl após digestão sulfúrica (Malavolta et al., 1997). Outra amostra do material sofreu digestão nítrico-perclórica, e no extrato foram determinados os teores de $\mathrm{P}$, por dosagem colorimétrica com molibdato de amônio, e de K, por fotometria de chama, e os teores de $\mathrm{Ca}$ e $\mathrm{Mg}$, por absorção atômica (Malavolta et al., 1997). Os conteúdos de nutrientes em cada porção vegetal foram calculados por meio do produto do teor do nutriente pela biomassa respectiva. Foram calculados os componentes de produção número de vagens por planta, número de sementes por vagem, massa de 100 grãos, índice de colheita (correspondente à razão entre a massa seca de grãos e de toda a parte aérea) e os índices de colheita de $\mathrm{N}, \mathrm{P}, \mathrm{K}, \mathrm{Ca}$ e $\mathrm{Mg}$ (pela razão entre os conteúdos do nutriente nos grãos e na parte aérea). Foi efetuada análise de variância para avaliar o efeito de genótipo e mensurar o coeficiente de variação de cada caráter. Foram estimadas as correlações fenotípicas, ambientais e genéticas entre as médias experimentais dos caracteres mensurados (Cruz \& Regazzi, 1997), cuja significância foi avaliada pelo teste $\mathrm{t}$.

\section{RESULTADOS E DISCUSSÃO}

\section{Variabilidade}

Os genótipos avaliados apresentaram datas de floração variando entre 29 e 37 dias após emergência, e maturação entre 70 e 89 dias após emergência (Quadro 1). Em regiões de baixa altitude e temperaturas médias entre 20 e $27^{\circ} \mathrm{C}$, a duração do ciclo do germoplasma cultivado de Phaseolus vulgaris varia entre 60 e 90 dias (Wallace, 1985), similar à amplitude de duração do ciclo dos materiais avaliados.

O rendimento médio de grãos foi de $205 \mathrm{~g} \mathrm{~m}^{-2}$ (Quadro 1), considerado adequado para as condições locais. A variação do rendimento foi de 113 a $280 \mathrm{~g} \mathrm{~m}^{-2}$, ou seja, uma amplitude de 2,5 vezes, demonstrando a diversidade do material estudado. $\mathrm{O}$ genótipo não nodulante NORH-54 teve menor rendimento, em razão da ausência de simbiose com rizóbio e um provável baixo fornecimento de $\mathrm{N}$ pela mineralização da matéria orgânica, com baixos teores no solo local. A cultivar Alessa, cultivada preferencialmente para produção de vagens verdes, também teve baixo rendimento de grãos (Quadro 1). Os maiores rendimentos foram obtidos pelas populações Pop 71 e Pop 59, selecionadas a partir de germoplasma coletado junto a agricultores na região Sul, e pela cultivar Manteigão (Quadro 1). O número de vagens por planta variou entre 4,1 e 10,2 nos diferentes genótipos (Quadro 2), demonstrando a ampla variabilidade desse caráter; já o número de grãos por vagens teve variação um pouco menor: entre 2,9 e 4,8 (Quadro 2). A massa de 100 grãos, um componente com maior controle genético (Ramalho et al., 1993), teve ampla variação em função da diversidade dos materiais avaliados.

O índice de colheita de biomassa variou de 0,54 a $0,71 \mathrm{~g} \mathrm{~g}^{-1}$ (Quadro 1), amplitude de variação similar à registrada em outros trabalhos com feijoeiro, conforme revisado por Araújo \& Teixeira (2003). A amplitude de variação do índice de colheita foi relativamente reduzida quando comparada à de outros caracteres (Quadro 2), reforçando a hipótese de que este é um caráter com pequena variabilidade em feijoeiro (Araújo \& Teixeira, 2003). Todavia, deve-se considerar que este índice é composto 
Quadro 2. Valores médios, mínimos e máximos e coeficiente de variação obtido na análise de variância, de caracteres mensurados na maturação de grãos de 64 genótipos de feijoeiro

\begin{tabular}{|c|c|c|c|c|}
\hline Caráter & Médio & Mínimo & Máximo & CV (\%) \\
\hline Produção de grãos ( $\mathrm{g} \mathrm{m}^{-2}$ ) & 205 & 113 & 280 & 18,48 \\
\hline Número de vagens por planta & 7,3 & 4,1 & 10,2 & 16,85 \\
\hline Número de grãos por vagem & 3,9 & 2,9 & 4,8 & 11,28 \\
\hline Massa de 100 grãos (g) & 31,9 & 18,0 & 58,8 & 8,93 \\
\hline Massa de caules $\left(\mathrm{g} \mathrm{m}^{-2}\right)$ & 60 & 40 & 81 & 18,80 \\
\hline Massa de palha de vagens $\left(\mathrm{g} \mathrm{m}^{-2}\right)$ & 47 & 28 & 68 & 15,21 \\
\hline Massa total de resíduos $\left(\mathrm{g} \mathrm{m}^{-2}\right)$ & 107 & 73 & 146 & 15,67 \\
\hline Conteúdo de $\mathrm{N}$ nos resíduos $\left(\mathrm{g} \mathrm{m}^{-2}\right)$ & 2,02 & 1,48 & 2,79 & 22,26 \\
\hline Conteúdo de $\mathrm{P}$ nos resíduos $\left(\mathrm{g} \mathrm{m}^{-2}\right)$ & 0,15 & 0,09 & 0,21 & 23,73 \\
\hline Conteúdo de $\mathrm{K}$ nos resíduos $\left(\mathrm{g} \mathrm{m}^{-2}\right)$ & 3,57 & 1,51 & 5,11 & 26,65 \\
\hline Conteúdo de Ca nos resíduos ( $\left.\mathrm{g} \mathrm{m}^{-2}\right)$ & 2,83 & 1,96 & 4,17 & 22,34 \\
\hline Conteúdo de $\mathrm{Mg}$ nos resíduos $\left(\mathrm{g} \mathrm{m}^{-2}\right)$ & 1,30 & 0,88 & 1,85 & 20,72 \\
\hline Conteúdo de $\mathrm{N}$ nos grãos $\left(\mathrm{g} \mathrm{m}^{-2}\right)$ & 10,32 & 6,06 & 13,78 & 18,24 \\
\hline Conteúdo de $\mathrm{P}$ nos grãos $\left(\mathrm{g} \mathrm{m}^{-2}\right)$ & 1,19 & 0,70 & 1,47 & 20,23 \\
\hline Conteúdo de K nos grãos ( $\left.\mathrm{g} \mathrm{m}^{-2}\right)$ & 4,97 & 2,37 & 6,81 & 24,10 \\
\hline Conteúdo de Ca nos grãos $\left(\mathrm{g} \mathrm{m}^{-2}\right)$ & 1,41 & 0,81 & 2,82 & 34,09 \\
\hline Conteúdo de $\mathrm{Mg}$ nos grãos $\left(\mathrm{g} \mathrm{m}^{-2}\right)$ & 1,39 & 0,82 & 2,43 & 27,22 \\
\hline Teor de N nos grãos $\left(\mathrm{mg} \mathrm{g}^{-1}\right)$ & 39,6 & 34,7 & 44,4 & 7,23 \\
\hline Teor de P nos grãos ( $\left.\mathrm{mg} \mathrm{g}^{-1}\right)$ & 4,54 & 3,76 & 5,33 & 10,67 \\
\hline Teor de K nos grãos (mg g-1) & 18,7 & 15,4 & 22,7 & 14,87 \\
\hline Teor de Ca nos grãos $\left(\mathrm{mg} \mathrm{g}^{-1}\right)$ & 5,4 & 3,2 & 9,4 & 27,86 \\
\hline Teor de $\mathrm{Mg}$ nos grãos (mg g-1) & 5,3 & 4,3 & 6,7 & 18,93 \\
\hline
\end{tabular}

pela razão entre duas variáveis, uma das quais (rendimento) está presente simultaneamente no numerador e denominador, e intrinsecamente apresenta menor variação (Sinclair, 1998). As populações Pop 59 e Pop 60 apresentaram os maiores índices de colheita, e os genótipos NORH-54 e BAT76, os menores (Quadro 1). Os índices de colheita são usualmente maiores em leguminosas de grãos que em outros cereais, pois em legumes as folhas não são consideradas nessa mensuração, já que são perdidas durante o ciclo de crescimento (Hay, 1995). Elevadas correlações em cultivares de soja entre os índices de colheita real e aparente (incluindo ou não as folhas senescentes, respectivamente) indicam que o índice de colheita mensurado apenas com base na biomassa na maturação pode refletir a capacidade de alocação de biomassa nos grãos de um determinado genótipo (Schapaugh Junior \& Wilcox, 1980). Entretanto, essa assertiva exige demonstração experimental para o feijoeiro, ausente na literatura.

Os índices de colheita de $\mathrm{N}, \mathrm{P}, \mathrm{K}, \mathrm{Ca}$ e $\mathrm{Mg}$ apresentaram valores médios de $0,83,0,89,0,58$, 0,33 e 0,51 g g-1, respectivamente (Quadro 1). Portanto, os índices de colheita de $\mathrm{N}$ e $\mathrm{P}$ foram bem superiores ao índice de colheita de biomassa, denotando que a translocação de $\mathrm{N}$ e $\mathrm{P}$ para formação dos grãos é mais intensa que a própria translocação de fotoassimilados (Araújo \& Teixeira, 2003). Por outro lado, os índices de colheita de $\mathrm{K}$ e $\mathrm{Mg}$ foram inferiores ao de biomassa, e o índice de colheita de $\mathrm{Ca}$, bem inferior aos demais, indicando a menor força do dreno para esses nutrientes durante a formação das sementes de feijão. As amplitudes de variação dos índices de colheita de $\mathrm{N}$ (0,73 a
0,89 $\left.\mathrm{g} \mathrm{g}^{-1}\right)$ e de $\mathrm{P}\left(0,84\right.$ a $\left.0,93 \mathrm{~g} \mathrm{~g}^{-1}\right)$ foram um pouco superiores às registradas por Araújo \& Teixeira (2003). Mesmo assim, são bastante estreitas as amplitudes de variação dos índices de colheita de $\mathrm{N}$ e $\mathrm{P}$, inclusive como expresso pelos baixos coeficientes de variação, indicando que a intensa força do dreno das sementes para $\mathrm{N}$ e $\mathrm{P}$, provavelmente sob estrito controle genético, reduz a plasticidade do feijoeiro em termos de partição destes nutrientes entre a biomassa e os grãos. Wolyn et al. (1991) observaram pequena variabilidade entre cultivares e progênies de feijoeiro nos padrões de distribuição de $\mathrm{N}$ na planta, indicando potencial limitado de seleção para o aumento da remobilização de $\mathrm{N}$ para os grãos.

A massa de caule na maturação variou entre 40 e $60 \mathrm{~g} \mathrm{~m}^{-2}$, e a massa de palha das vagens, entre 28 e $47 \mathrm{~g} \mathrm{~m}^{-2}$ (Quadro 2), ou seja, similar à amplitude de variação da produção de grãos. Esses resultados indicam que alguns genótipos de feijoeiro podem produzir $1,5 \mathrm{Mg} \mathrm{ha}^{-1}$ de resíduos após trilhagem dos grãos, para um rendimento de grãos da ordem de $2,5 \mathrm{Mg} \mathrm{ha}^{-1}$, os quais podem representar elevado aporte de matéria orgânica aos sistemas de produção. Os resíduos obtidos após a trilhagem de grãos continham em média 20, 1,5, 36, 28 e $13 \mathrm{~kg} \mathrm{ha}^{-1}$ de N, P, K, Ca e Mg, respectivamente (Quadro 2), indicando que esses materiais, caso adequadamente manejados, podem restituir quantidades relativamente elevadas de nutrientes ao solo. Chagas et al. (2007) reportaram valores de 1,2 $\mathrm{Mg} \mathrm{ha}^{-1}$ de resíduos gerados após a trilhagem dos grãos de feijão, que continham 9,9 e $0,71 \mathrm{~kg} \mathrm{ha}^{-1}$ de $\mathrm{N}$ e P, respectivamente. Já Araújo \& Teixeira (2003) reportaram, em 18 cultivares, massa 
de resíduos entre 0,6 e $1,5 \mathrm{Mg}^{-1}$, que continham entre 5 e $12 \mathrm{~kg} \mathrm{ha}^{-1}$ de $\mathrm{N}$ e entre 0,4 e $1,0 \mathrm{~kg} \mathrm{ha}^{-1} \mathrm{de} \mathrm{P}$.

Cabe destacar que os conteúdos de $\mathrm{P}$ nos resíduos, apesar de menor magnitude, representaram $12 \%$ do total de $\mathrm{P}$ acumulado pela cultura na maturação (Quadro 2). Diante da baixa eficiência da adubação fosfatada nos solos tropicais, a incorporação de resíduos ricos em $\mathrm{P}$ pode propiciar liberação paulatina de $\mathrm{P}$ orgânico, menos suscetível a fenômenos de adsorção, e o retorno desses resíduos ao solo pode contribuir com o crescimento de cultivos subsequentes (Nuruzzaman et al., 2005). Entretanto, a relativamente lenta decomposição desses resíduos pode não ser suficiente para suprir totalmente as demandas de cultivos em início de crescimento (Nachimuthu et al., 2009). Chagas et al. (2007) verificaram meia-vida de 179 e 64 dias de caules e palha de vagens gerados após a trilhagem dos grãos de feijão, respectivamente; essa relativamente lenta decomposição foi associada à sua relação $\mathrm{C}: \mathrm{N}$ acima de 60. A liberação de $\mathrm{N}$ e $\mathrm{P}$ desses resíduos foi similar à dinâmica de decomposição, enquanto a liberação de $\mathrm{K}$ foi mais rápida (Chagas et al., 2007).

As cultivares de feijoeiro acumularam nos grãos 100, 12, 50, 14 e $14 \mathrm{~kg} \mathrm{ha}^{-1}$ de N, P, K, Ca e Mg, respectivamente (Quadro 2), para um rendimento médio de $2,1 \mathrm{Mg} \mathrm{ha}^{-1}$, ou seja, elevadas quantidades de nutrientes são exportadas pela cultura por meio dos grãos colhidos. Considerando que $83 \%$ do N acumulado pelo cultivo na maturação estava contido nos grãos (Quadro 2), mesmo admitindo-se elevada estimativa de $70 \%$ do $\mathrm{N}$ derivado da fixação biológica em campo (Hardarson et al., 1993), o balanço líquido de $\mathrm{N}$ deve ser negativo para a cultura do feijão, com maior quantidade de $\mathrm{N}$ exportado nos grãos do que a fixada simbioticamente durante o cultivo. Entretanto, esse balanço não considera o aporte de $\mathrm{N}$ oriundo das folhas senescidas durante o ciclo de crescimento, não mensuradas no presente trabalho.

A amplitude de variação entre genótipos nos teores de $\mathrm{N}$ nos grãos foi a mais estreita entre os nutrientes mensurados (Quadro 2). Os elevados teores de proteína nos grãos de leguminosas estão associados a alto custo energético para formação das sementes, que explicam parcialmente seus menores rendimentos de grãos em comparação a outros cereais (Munier-Jolain \& Salon, 2005). A variação nos teores de $\mathrm{P}, \mathrm{K}$ e $\mathrm{Mg}$ nos grãos foi de magnitude similar, e a variação nos teores de Ca nos grãos foi a mais ampla (Quadro 2).

\section{Correlações entre caracteres}

A produção de grãos apresentou correlações fenotípicas e genéticas negativas altamente significativas com os dias para floração; as correlações fenotípicas e genéticas entre produção de grãos e dias para maturação também foram negativas, porém menos significativas (Quadro 3). Dessa forma, nas

Quadro 3. Correlações fenotípicas, ambientais e genéticas entre produção de grãos, componentes de produção, índices de colheita de biomassa e de nutrientes e conteúdos e teores de nutrientes nos grãos, em 64 cultivares de feijoeiro

\begin{tabular}{|c|c|c|c|}
\hline Caracter & Fenotípica & Ambiental & Genética \\
\hline \multicolumn{4}{|c|}{ Correlação com a produção de grãos } \\
\hline Dias para floração & $-0,460 * * *$ & $-0,160$ & $-0,557 * * *$ \\
\hline Dias para maturação & $-0,292^{*}$ & 0,035 & $-0,387 * *$ \\
\hline Massa de parte aérea & $0,954 * * *$ & $0,971 * * *$ & $0,945 * * *$ \\
\hline Número de vagens por planta & $-0,245$ & $0,496 * * *$ & $-0,453 * * *$ \\
\hline Número de grãos por vagem & $-0,283^{*}$ & $0,467 * * *$ & $-0,582 * * *$ \\
\hline Massa de 100 grãos & $0,618 * * *$ & 0,187 & $0,754 * * *$ \\
\hline Índice de colheita & $0,569 * * *$ & $0,536 * * *$ & $0,592 * * *$ \\
\hline Índice de colheita de $\mathrm{N}$ & $0,504 * * *$ & $0,415 * * *$ & $0,556 * * *$ \\
\hline Índice de colheita de $\mathrm{P}$ & $0,400 * *$ & $0,457 * * *$ & $0,368 * *$ \\
\hline Índice de colheita de $\mathrm{K}$ & $0,278^{*}$ & 0,162 & $0,341^{* *}$ \\
\hline Índice de colheita de $\mathrm{Ca}$ & 0,115 & 0,138 & 0,105 \\
\hline Índice de colheita de $\mathrm{Mg}$ & $0,396 * *$ & $0,316^{*}$ & $0,458 * * *$ \\
\hline Teor de N no grão & $-0,570 * * *$ & $-0,245$ & $-0,739 * * *$ \\
\hline Teor de $\mathrm{P}$ no grão & $-0,553 * * *$ & $-0,144$ & $-0,826^{* * *}$ \\
\hline Teor de K no grão & $-0,016$ & 0,039 & $-0,086$ \\
\hline Teor de Ca no grão & $-0,209$ & $-0,014$ & $-0,477 * * *$ \\
\hline Teor de Mg no grão & $-0,029$ & 0,034 & $-0,130$ \\
\hline Conteúdo de $\mathrm{N}$ no grão & $0,931 * * *$ & $0,933 * * *$ & $0,938 * * *$ \\
\hline Conteúdo de $\mathrm{P}$ no grão & $0,885 * * *$ & $0,835^{* * *}$ & $0,913^{* * *}$ \\
\hline Conteúdo de $\mathrm{K}$ no grão & $0,858 * * *$ & $0,776 * * *$ & $0,934 * * *$ \\
\hline Conteúdo de Ca no grão & $0,495 * * *$ & $0,391 * * *$ & $0,680 * * *$ \\
\hline Conteúdo de Mg no grão & $0,827 * * *$ & $0,723 * * *$ & $0,912 * * *$ \\
\hline \multicolumn{4}{|c|}{ Correlação com o índice de colheita } \\
\hline Dias para maturação & 0,016 & 0,195 & $-0,013$ \\
\hline Massa de caule & $-0,479 * * *$ & $-0,326 * *$ & $-0,547 * * *$ \\
\hline
\end{tabular}

$*, * *, * * *$ significativo a 5,1 e $0,1 \%$ pelo teste $t$. 
condições em que foi conduzido o experimento, os materiais precoces apresentaram maior potencial produtivo que os materiais tardios. Cabe ressaltar que as correlações fenotípicas são influenciadas pelo genótipo e pelo ambiente, as correlações genéticas são atribuídas à pleiotropia (múltiplos efeitos de um mesmo gene) e ao linkage (genes ligados em um mesmo cromossomo), enquanto as correlações ambientais refletem a similaridade da resposta de dois caracteres a um ambiente comum (Scully et al., 1991). Nesse mesmo local experimental, Araújo \& Teixeira (2003) também verificaram correlações negativas entre rendimento de grãos e dias para maturação em 18 cultivares de feijoeiro.

As correlações fenotípicas, ambientais e genéticas entre a produção de grãos e a biomassa total de parte aérea foram positivas e muito elevadas (Quadro 3), mas deve-se considerar que esses caracteres são intrinsecamente correlacionados, pois a biomassa total inclui a massa de grãos. A produção de grãos apresentou correlações genéticas negativas com o número de vagens por planta e o número de grãos por vagem, com correlações fenotípicas e genéticas positivas com a massa de 100 grãos (Quadro 3). Apesar das dificuldades para comparar estimativas das correlações entre componentes de produção no feijoeiro, em virtude dos intensos efeitos compensatórios entre esses caracteres, o número de vagens por planta costuma apresentar-se como o componente com maior participação na produção de grãos (Ramalho et al., 1993). Assim, as correlações entre a produção de grãos e os componentes de produção obtidas neste trabalho (Quadro 3) são pouco usuais, porém são consequência dos maiores rendimentos de materiais de ciclo mais curto e com sementes de maior tamanho, a exemplo de Pop 59, Pop 71, Manteigão e Constanza (Quadro 1). $\mathrm{Na}$ verdade, as correlações fenotípicas entre produção de grãos e dias para maturação tornamse não significativas quando calculadas dentro de cada hábito de crescimento, demonstrando que a correlação negativa entre rendimento e duração do ciclo (Quadro 3) teve marcada influência do hábito de crescimento. Além disso, a correlação fenotípica entre produção de grãos e número de vagens por planta foi altamente significativa $(r$ $=0,57, \mathrm{p}<0,001)$ para os genótipos de hábito de crescimento III.

As correlações fenotípicas e genéticas entre produção de grãos e índice de colheita foram positivas e significativas (Quadro 3), com valores superiores aos revisados por Araújo \& Teixeira (2003) em feijoeiro. Ademais, a correlação ambiental positiva entre esses caracteres indica resposta semelhante a variações do ambiente. Dessa forma, apesar de a produção de grãos estar fortemente associada à produção de biomassa, a seleção para índice de colheita pode resultar em incrementos adicionais no rendimento. Hay (1995) sugere que a maioria dos principais cultivos de cereais pode ter atingido o limite superior do índice de colheita e que futuros ganhos de rendimento terão de ser obtidos por meio de incrementos na produção de biomassa, o que, segundo Sinclair (1998), exigirá maior aquisição de $\mathrm{N}$ pelos cultivos.

O índice de colheita foi negativamente correlacionado com a massa de caule na maturação (Quadro 3), pois materiais de porte ereto, com maior massa de caule, apresentam menor índice de colheita, sem que isso signifique necessariamente menor eficiência de translocação de biomassa para os grãos (Araújo \& Teixeira, 2003). Isso é confirmado pelo menor índice de colheita dos genótipos de crescimento prostrado (tipo III), em comparação aos de crescimento ereto (Quadro 1). O índice de colheita não se correlacionou com os dias para maturação (Quadro 3), indicando que a seleção para índice de colheita pode ser efetuada de forma independente da duração do ciclo da cultura.

A produção de grãos teve correlações fenotípicas, ambientais e genéticas altamente significativas $(\mathrm{p}<0,1 \%)$ com o índice de colheita de $\mathrm{N}$, indicando que o maior rendimento esteve estreitamente associado a uma maior alocação de $\mathrm{N}$ nos grãos. Já as correlações fenotípicas e genéticas entre rendimento e índice de colheita de $\mathrm{P}$ foram significativas a $1 \%$ (Quadro 3 ). Em razão das relações menos estreitas entre esses caracteres, foi possível identificar alguns materiais com baixo índice de colheita de $\mathrm{P}$, porém com bom rendimento de grãos, como Jalo Precoce, Linha 29 (Jalo) e Linha 08 (Iraí) (Quadro 1). Vislumbra-se, assim, a possibilidade de seleção, ainda que limitada pela presença das correlações genéticas, de cultivares com bom rendimento e baixo índice de colheita de $\mathrm{P}$, reduzindo a remoção desse nutriente pela colheita do feijão. As correlações fenotípicas e genéticas do rendimento com os índices de colheita de $\mathrm{K}$ e $\mathrm{Mg}$ também foram significativas, sem relações com 0 índice de colheita de Ca (Quadro 3).

A produção de grãos teve elevadas correlações com os conteúdos de nutrientes nos grãos (Quadro 3), demonstrando que o rendimento está associado à acumulação de nutrientes nos grãos. A partir de avaliações do rendimento de grãos e da acumulação de biomassa e nutrientes em vários estádios ontogenéticos em dois experimentos de campo, Araújo \& Teixeira (2008) propuseram que uma contínua aquisição de $\mathrm{N}$ e $\mathrm{P}$ durante o enchimento de vagens esteve associada a maiores rendimentos de cultivares de feijoeiro. Foram obtidas elevadas correlações fenotípicas e genéticas negativas entre produção de grãos e teores de $\mathrm{N}$ e $\mathrm{P}$ nos grãos (Quadro 3), ou seja, a seleção para elevado rendimento pode vir acompanhada de diluição de $\mathrm{N} \mathrm{e}$ $\mathrm{P}$ nos grãos. Já as correlações entre rendimento e os teores de $\mathrm{K}$ e Mg nos grãos não foram significativas, 
verificando-se apenas uma correlação genética negativa com o teor de $\mathrm{Ca}$ (Quadro 3). Araújo \& Teixeira (2003) verificaram, por meio de análises de regressão múltipla, que a maior parte da variação do rendimento de grãos em cultivares de feijoeiro esteve associada à quantidade de $\mathrm{N}$ e $\mathrm{P}$ acumulada na maturação e que parte dessa variação foi associada à variação nos teores de $\mathrm{N}$ e $\mathrm{P}$ nos grãos, com os índices de colheita de $\mathrm{N}$ e $\mathrm{P}$ assumindo menor relevância.

Baixos teores de $\mathrm{P}$ no grão podem reduzir o teor de fitina, a qual representa de 54 a $82 \%$ do conteúdo total de P do feijão e está associada a sintomas de deficiência nutricional em seres humanos e animais (Lolas \& Markakis, 1975). Todavia, plantas de feijão originadas de sementes com alto teor de $\mathrm{P}$ produziram maior massa de parte aérea e nódulos e foram menos responsivas ao suprimento de P no solo do que plantas oriundas de sementes com baixo teor de P (Teixeira et al., 1999), além de apresentarem maior contribuição do $\mathrm{N}$ oriundo da fixação biológica (Chagas et al., 2010). Assim, delineia-se um aspecto contraditório para definição de um ideótipo para eficiência de utilização de $\mathrm{P}$ em leguminosas de grão. A redução do teor de $\mathrm{P}$ no grão pode melhorar sua qualidade nutricional e diminuir a retirada do nutriente do sistema; contudo, altos teores de P nas sementes propiciam maior crescimento e nodulação e seriam desejáveis para a maior eficiência da simbiose com bactérias diazotróficas.

Os resultados indicam que a seleção de genótipos de feijoeiro para maior rendimento de grãos deve resultar em uma seleção indireta para maiores índices de colheita de biomassa e de $\mathrm{N}$, bem como para maiores quantidades de nutrientes nos grãos. As menores correlações observadas entre rendimento e índice de colheita de $\mathrm{P}$ indicam uma possibilidade, ainda que restrita, de seleção de genótipos com bom rendimento, mas com menor remoção de $\mathrm{P}$ pelos grãos. Apesar das elevadas proporções de nutrientes exportadas pelos grãos, os resíduos produzidos após a trilhagem dos grãos contêm quantidades de nutrientes relativamente elevadas em comparação às demandas da cultura, o que recomenda um manejo que propicie seu retorno ao solo. Constata-se que uma avaliação mais precisa do balanço de nutrientes na cultura do feijão demanda a mensuração das folhas senescentes produzidas durante o ciclo de crescimento, inexistente na literatura.

\section{CONCLUSÕES}

1. Os genótipos de feijoeiro tiveram índices de colheita médios de $0,62,0,83,0,89,0,58,0,33$ e $0,51 \mathrm{~g} \mathrm{~g}^{-1}$, respectivamente, para biomassa, N, P, $\mathrm{K}$, Ca e Mg, o que indica intensa translocação de $\mathrm{N}$ e P para os grãos, sendo relativamente estreita a variabilidade desses índices.
2. A seleção de genótipos de feijoeiro para maior rendimento de grãos pode resultar em maiores índices de colheita de biomassa e de $\mathrm{N}$, assim como em maiores quantidades de nutrientes nos grãos e menores teores de $\mathrm{N}$ e $\mathrm{P}$ nos grãos.

\section{LITERATURA CITADA}

ARAÚJO, A.P. \& TEIXEIRA, M.G. Nitrogen and phosphorus harvest indices of common bean cultivars: implications for yield quantity and quality. Plant Soil, 257:425-433, 2003.

ARAÚJO, A.P. \& TEIXEIRA, M.G. Relationships between grain yield and accumulation of biomass, nitrogen and phosphorus in common bean cultivars. R. Bras. Ci. Solo, 32:1977-1986, 2008

CHAGAS, E.; ARAÚJO, A.P.; TEIXEIRA, M.G. \& GUERRA, J.G.M. Decomposição e liberação de nitrogênio, fósforo e potássio de resíduos da cultura do feijoeiro. R. Bras. Ci. Solo, 31:723-729, 2007.

CHAGAS, E.; ARAÚJO, A.P.; ALVES, B.J.R. \& TEIXEIRA, M.G. Seeds enriched with phosphorus and molybdenum improve the contribution of biological nitrogen fixation to common bean as estimated by ${ }^{15} \mathrm{~N}$ isotope dilution. R. Bras. Ci. Solo, 34:1093-1101, 2010.

CRUZ, C.D. \& REGAZZI, A.J. Modelos biométricos aplicados ao melhoramento genético. 2.ed. Viçosa, MG, Universidade Federal de Viçosa, 1997. 390p.

EGLI, D.B. The role of seed in the determination of yield of grain crops. Austr. J. Agric. Res., 57:1237-1247, 2006.

EMPRESA BRASILEIRA DE PESQUISA AGROPECUÁRIA - EMBRAPA. Centro Nacional de Pesquisa de Solos. Manual de métodos de análise de solo. 2.ed. Rio de Janeiro, 1997. $212 \mathrm{p}$

HARDARSON, G.; BLISS, F.A.; CIGALES-RIVERO, M.R.; HENSON, R.A.; KIPE-NOLT, J.A.; LONGERI, L.; MANRIQUE, A.; PEÑA-CABRIALES, J.J.; PEREIRA, P.A.A.; SANABRIA, C.A. \& TSAI, S.M. Genotypic variation in biological nitrogen fixation by common bean. Plant Soil, 152:59-70, 1993.

HAY, R.K.M. Harvest index: A review of its use in plant breeding and crop physiology. Ann. Appl. Biol., 126:197-216, 1995.

INSTITUTO BRASILEIRO DE GEOGRAFIA E ESTATÍSTICA IBGE. Censo Agropecuário 2006. Disponível em: www.ibge. gov.br/home/estatistica/economia/agropecuaria/censoagro/ brasil_2006. Acesso em 20 out. 2009.

JIN, J.; LIU, X.; WANG, G.; MI, L.; SHEN, Z.; CHEN, X. \& HERBERT, S.J. Agronomic and physiological contributions to the yield improvement of soybean cultivars released from 1950 to 2006 in Northeast China. Field Crops Res., 115:116-123, 2010.

KELLY, J.D.; KOLKMAN, J.M. \& SCHNEIDER, K. Breeding for yield in dry bean (Phaseolus vulgaris L.). Euphytica, 102:343-356, 1998. 
LAL, R. Global potential of soil carbon sequestration to mitigate the greenhouse effect. Crit. Rev. Plant Sci., 22:151-184, 2003.

LOLAS, G.M. \& MARKAKIS, P. Phytic acid and other phosphorus compounds of beans (Phaseolus vulgaris L.). J. Agric. Food Chem., 23:13-15, 1975.

LYNCH, J. \& WHITE, J.W. Shoot nitrogen dynamics in tropical common bean. Crop Sci., 32:392-397, 1992.

MALAVOLTA, E.; VITTI, G.C. \& OLIVEIRA, S.A. Avaliação do estado nutricional das plantas. 2.ed. Piracicaba, Associação Brasileira para Pesquisa da Potassa e do Fosfato, 1997. 319p.

MUNIER-JOLAIN, N.G. \& SALON, C. Are the carbon costs of seed production related to the quantitative and qualitative performance? An appraisal for legume and other crops. Plant Cell Environ., 28:1388-1395, 2005.

NACHIMUTHU, G.; GUPPY, C.; KRISTIANSEN, P. \& LOCWOOD, P. Isotopic tracing of phosphorus uptake in corn from ${ }^{33} \mathrm{P}$ labelled legume residues and ${ }^{32} \mathrm{P}$ labelled fertilisers applied to a sandy loam soil. Plant Soil, 314:303-310, 2009.

NURUZZAMAN, M.; LAMBERS, H.; BOLLAND, M.D.A. \& VENEKLAAS, E.J. Phosphorus benefits of different legume crops to subsequent wheat grown in different soils of Western Australia. Plant Soil, 271:175-187, 2005.

RAMALHO, M.A.P.; SANTOS, J.B. \& ZIMMERMANN, M.J.O. Genética quantitativa em plantas autógamas; aplicações ao melhoramento do feijoeiro. Goiânia, Universidade Federal de Goiás, 1993. 271p.

RICHARDS, R.A. Selectable traits to increase crop photosynthesis and yield of grain crops. J. Exper. Bot., 51:447-458, 2000.

RODRIGUES, L.S.; ANTUNES, I.F.; TEIXEIRA, M.G. \& SILVA, J.B. Divergência genética entre cultivares locais e cultivares melhoradas de feijão. Pesq. Agropec. Bras., 37:1275-1284, 2002.
SCHAPAUGH JUNIOR, W.T. \& WILCOX, J.R. Relationships between harvest indices and other plant characteristics in soybeans. Crop Sci., 20:529-533, 1980.

SCULLY, B.T.; WALLACE, D.H. \& VIANDS, D.R. Heritability and correlation of biomass, growth rates, harvest index, and phenology to the yield of common beans. J. Am. Soc. Hortic. Sci., 116:127-130, 1991.

SHAH, Z.; SHAH, S.H.; PEOPLES, M.B.; SCHWENKE, G.D. $\&$ HERRIDGE, D.F. Crop residue and fertiliser $\mathrm{N}$ effects on nitrogen fixation and yields of legume-cereal rotations and soil organic fertility. Field Crops Res., 83:1-11, 2003.

SINCLAIR, T.R. Historical changes in harvest index and crop nitrogen accumulation. Crop Sci., 38:638-643, 1998.

SINGH, S.P. Broadening the genetic base of common bean cultivars: a review. Crop Sci., 41:1659-1675, 2001.

TAR'AN, B.; MICHAELS, T.E. \& PAULS, K.P. Genetic mapping of agronomic traits in common bean. Crop Sci., 42:544-556, 2002.

TEIXEIRA, M.G.; GUERRA, J.G.M.; ALMEIDA, D.L.; ARAÚJO, A.P. \& FRANCO, A.A. Effect of seed phosphorus concentration on nodulation and growth of three common bean cultivars. J. Plant Nutr., 22:1599-1611, 1999.

WALLACE, D.H. Physiological genetics of plant maturity, adaptation and yield. Plant Breed. Rev., 3:21-167, 1985.

WOLYN, D.J.; ST. CLAIR, D.A.; DUBOIS, J.; ROSAS, J.C.; BURRIS, R.H. \& BLISS, F.A. Distribution of nitrogen in common bean (Phaseolus vulgaris L.) genotypes selected for differences in nitrogen fixation ability. Plant Soil, 138:303$311,1991$.

YAN, W. \& WALLACE, D.H. Breeding for negatively associated traits. Plant Breed. Rev., 13:141-177, 1995. 